\title{
Evaluation of Pulmonary Function in Adults with Grade III Obesity
}

\author{
Cássio Daniel Araújo da Silva1, Fernanda Figueirôa Sanchez ${ }^{1}$, Jonas Silva de Souza², \\ Jamilly Rebouças Demosthenes Marques', Ana Fátima de Freitas², Ellen Kathellen Sá de Souza1, \\ Roberta Lins Gonçalves ${ }^{1}$
}

${ }^{1}$ Federal University of Amazonas-UFAM, Manaus, Brazil

${ }^{2}$ Adriano Jorge Hospital Foundation-FHAJ, Manaus, Brazil

Email: cd.danielsilva@gmail.com

How to cite this paper: da Silva, C.D.A., Sanchez, F.F., de Souza, J.S., Marques, J.R.D., de Freitas, A.F., de Souza, E.K.Sá and Gonçalves, R.L. (2017) Evaluation of Pulmonary Function in Adults with Grade III Obesity. Health, 9, 942-950. https://doi.org/10.4236/health.2017.96067

Received: April 1, 2017

Accepted: June 20, 2017

Published: June 23, 2017

Copyright $\odot 2017$ by authors and Scientific Research Publishing Inc. This work is licensed under the Creative Commons Attribution International License (CC BY 4.0).

http://creativecommons.org/licenses/by/4.0/

\section{(c) (i) Open Access}

\begin{abstract}
Pulmonary function studies in obese individuals have alerted the pathophysiological changes due to weight gain. However, these changes are not fully explained yet. Objective: To evaluate and analyze the pulmonary function of obese adults in the city of Manaus (AM, Brazil) and to correlate the parameters of spirometry with weight and BMI. Method: A descriptive cross-sectional study, in which pulmonary function of 22 adults with grade III obesity was evaluated pre and post bronchodilator administration, performed at the Adriano Jorge Hospital Foundation-FHAJ. Results: Of the 22 patients evaluated, 6 were male and 16 were female; mean age was $37.1 \pm 7.4$ years, with a weight of $134.2 \pm 28.6 \mathrm{~kg}$ and a BMI of $51.1 \pm 9.4 \mathrm{~kg} / \mathrm{m}^{2}$, corresponding to grade III obesity. Spirometry showed a reduction in values obtained from Forced Vital Capacity (FVC), Forced Expiratory Volume in the first second (FEV1) and Peak Expiratory Flow (PEF) in relation to those predicted, with $23 \%$ of restrictive disorders. There were negative correlations between BMI and PEF, weight and FVC, weight and PEF. The P value for correlation of weight and FEV1 is not statistically significant. Conclusion: Restrictive and obstructive disorders are prevalent in the population with grade III obesity. Correlations between pulmonary function and $\mathrm{BMI} /$ weight were negative for this specific population.
\end{abstract}

\section{Keywords}

Respiratory Muscles, Spirometry, Obesity, Evaluation

\section{Introduction}

Obesity is a chronic disease, non-transmissible, with multifactorial character and 
systemic repercussions [1] [2] [3]. This disease has become a major health and social problem in the last decades, being considered an important health problem in this century [1] [2] [3]. Global estimates by the World Health Organization (WHO) indicated that in 2015, 2.3 billion adults would be overweight and more than 700 million would be obese [4]. In Brazil, there are reported of $32 \%$ of the adult population were overweight, of which, $8 \%$ have obesity [5].

Characterized by the disorder that includes the excessive consumption of caloric foods in detriment of a low energy expenditure, sedentarism as lifestyle habits [3] [5] [6] [7] [8], sociological factors and metabolic and neuroendocrine changes, as well as hereditary gene components are involved [9]. Among all the clinical repercussions of obesity, such as increased rates of cardiovascular diseases, musculoskeletal disorders, metabolic disturbances of inflammatory cascades and reduction of life expectancy [1] [2] [6] [9] [10] [11], respiratory comorbidities have gained importance nowadays, with pertinent investigations about influence of the weight gain and its physiological adaptations that can culminate in singular pathological situations [12] [13]. Thus, for example, the biomechanical disadvantage of the respiratory system against the resistance imposed by adipose tissue deposited under the thoracic/abdominal cavity has become a consensus [14] [15]. However, the physiological mechanisms involved and the other repercussions of this situation are not yet fully elucidated in the literature [11] [12] [13] [14] [15].

One of the most practical and performed functional evaluations in pulmonology is the pulmonary function test, which allows quantifying airflow during forced respiratory incursions and identifies restrictive and/or obstructive airway disorders [7] [8] [9] [10] [11]. In the obese population, a large part of studies indicate a relation between restrictive disorders and an increase in BMI, with obstructive disorders-in theory-reserved for special conditions, such as asthma and obstructive sleep apnea [12].

Considering the range of speculation and conflicting results reported by research, and also its population and methodological characteristics, this study aims to evaluate and analyze pulmonary function of obese adults in the city of Manaus (AM, Brazil), and correlate the parameters of spirometry with weight and BMI.

\section{Methods}

\subsection{Trial Design and Sample}

This is a descriptive cross-sectional study approved by the Research Ethics Committee of the Federal University of Amazonas-UFAM (AM), CAAE: 01840212.0.0000.5020, in which pulmonary function was evaluated before and after administration of bronchodilator in 22 adult individuals with grade III obesity of the Bariatric Surgery Program from Adriano Jorge Hospital Foundation. The study was carried out between March and June 2015. All volunteers were instructed about the study procedures and signed the Informed Consent Form (TCLE). Individuals were included in the research as they presented the eligibil- 
ity criteria, namely: have a clinical diagnosis of obesity, do not smoke, and present a clinical situation with no history of recent illness and adequate physical-cognitive capacity to perform the exam. Exclusion criteria included individuals with a history of respiratory or cardiovascular disease. No subjects were excluded from the study. During the anamnesis an evaluation record was filled out with questions about smoking, presence of respiratory and cardiovascular dysfunction, family history and medications in use. After that, anthropometric measurements were collected and the subjects were referred for evaluation.

\subsection{Body Mass Index}

BMI was calculated using the following formula: BMI = weight $(\mathrm{kg}) / \mathrm{height} 2\left(\mathrm{~m}^{2}\right)$, and categorized considering the ranges of $30-34.9 \mathrm{~kg} / \mathrm{m}^{2}$ for diagnosis of obesity stage I; 35 to $39.9 \mathrm{~kg} / \mathrm{m}^{2}$ for obesity stage II and $\geq 40 \mathrm{~kg} / \mathrm{m}^{2}$ for stage III obesity, also known as morbid obesity, according to World Health Organization (WHO) [1] [4].

\subsection{Spirometry}

For evaluation of pulmonary function was used Portable Spirometer MicroLab 3500 (Spida Software, model MK8/Cardinal Health). The test was performed in seated position, with single use disposable mouthpieces, nasal clip and previous instructions, according to the recommendations of the Guidelines for pulmonary function tests of the American Thoracic Society (ATS) [16] and Brazilian Society of Pulmonology and Tisiology: SBPT [17], pre and post-bronchodilator test, applied by the same trained technician.

The measures obtained were: Forced Vital Capacity (FVC), Forced Expiratory Volume in 1 second (FEV1), FEV1/FVC ratio and Peak Expiratory Flow (PEF). All measures were expressed in absolute terms and percentages of predicted, being analyzed according to the reference values proposed by ATS/GOLD 2015 [18]. The results were classified in spirometry normal, Obstructive Ventilatory Disorder (OVD) and Restrictive Ventilator Disorder (RVD). For statistical analysis and classification of pulmonary function parameters, the values of the examination performed after bronchodilator administration were considered as reference.

\subsection{Statistical Analysis}

Data were processed in the SigmaStat Software version 3.5 for the simple average calculation, the average standard deviation and application of Student's T-test and Spearman's correlation coefficient between pulmonary function parameters and the variables weight and BMI.

\section{Results}

From the total of 22 patients evaluated, 6 were male and 16 female, mean age $37.1 \pm$ 7.4 years, weighing $134.2 \pm 28.6 \mathrm{~kg}$ and BMI $51.1 \pm 9.4 \mathrm{~kg} / \mathrm{m}^{2}$, corresponding to grade III obesity. As shown in Figure 1, restrictive (23\%) and obstructive (18\%) ven- 
tilatory disorders were found in the studied population, although with a higher prevalence of normal pulmonary function tests (59\%). Due to the small sample of the study, it was not possible to classify ventilatory disorders by gender.

In the general analysis of the 22 individuals without categorizing them by respiratory disturbs, the results were FVC and FEV1 both with $83 \%$ of predicted, PEF $69 \%$ of predicted $(\mathrm{P}=0.001)$, and FEV1/FVC ratio was unchanged. Comparing the absolute values before and after bronchodilator lung volumes, we observed that there was no significant difference in post-BD data, as shown in $\mathrm{Ta}$ ble 1.

The results of lung function measurements in the study, as \% predicted, are detailed in Table 2.

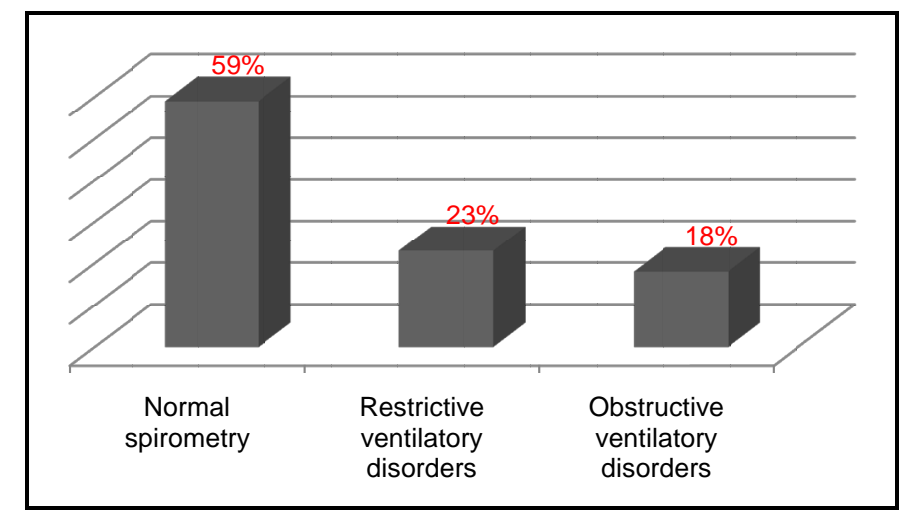

Figure 1. Classification of ventilatory disorders in obesity grade III.

Table 1. Pulmonary function test performed before and after bronchodilator in individuals with morbid obesity categorized by type of ventilatory disorder.

\begin{tabular}{ccccccccc}
\hline \multirow{2}{*}{$\begin{array}{c}\text { Ventilatory } \\
\text { function }\end{array}$} & \multicolumn{4}{c}{ OBTAINED Before-BD* } & & & \multicolumn{3}{c}{ OBTAINED After-BD* $^{*}$} \\
\cline { 2 - 9 } & FEV1 & FVC & FEV1/FVC & PEF & FEV1 & FVC & FEV1/FVC & PEF \\
\hline Normal & $2.72 \pm 0.48$ & $3.24 \pm 0.73$ & $84.00 \pm 5.90$ & $5.95 \pm 1.44$ & $2.84 \pm 0.46$ & $3.27 \pm 0.62$ & $87.60 \pm 5.10$ & $6.08 \pm 1.43$ \\
OVD & $2.00 \pm 0.32$ & $2.58 \pm 0.20$ & $77.50 \pm 9.20$ & $4.73 \pm 2.11$ & $2.07 \pm 0.35$ & $2.71 \pm 0.28$ & $75.00 \pm 6.50$ & $4.86 \pm 2.02$ \\
RVD & $2.75 \pm 0.41$ & $3.20 \pm 0.52$ & $87.00 \pm 7.70$ & $5.47 \pm 2.03$ & $2.52 \pm 0.63$ & $2.94 \pm 0.68$ & $87.40 \pm 10.30$ & $5.26 \pm 2.06$ \\
\hline
\end{tabular}

BD: Bronchodilator; FEV1: Forced Expiratory Volume in the first second; FVC: Forced Vital Capacity; FEV1/FVC: Expiratory Volume Forced in the first second on Forced Vital Capacity; PFE: Peak Expiratory Flow; OVD: Obstructive Ventilatory Disorder; RVD: Restrictive Ventilatory Disorder. ${ }^{*}$ No significant statistical differences.

Table 2. Measurements of lung function, as a percentage of predicted, of 22 individuals with morbid obesity categorized by type of ventilatory disorder.

\begin{tabular}{|c|c|c|c|c|c|c|c|c|}
\hline \multirow{2}{*}{$\begin{array}{l}\text { Ventilatory } \\
\text { function }\end{array}$} & \multicolumn{2}{|c|}{ FEV1 } & \multicolumn{2}{|c|}{ FCV } & \multicolumn{2}{|c|}{ FEV1/FVC } & \multicolumn{2}{|c|}{ PFE } \\
\hline & Before - BD & After - BD & Before - BD & After - BD & Before - BD & After - BD & Before - BD & After - BD \\
\hline Normal & $90.10 \pm 8.90$ & $94.6 \pm 8.40$ & $90.6 \pm 9.20$ & $91.70 \pm 7.60$ & $101.30 \pm 9.20$ & $105.00 \pm 7.00$ & $83.55 \pm 23.11$ & $84.89 \pm 16.73$ \\
\hline OVD & $68.70 \pm 17.80$ & $70.30 \pm 12.30$ & $75.2 \pm 8.10$ & $78.70 \pm 13.80$ & $92.20 \pm 11.50$ & $90.00 \pm 8.70$ & $48.83 \pm 11.42$ & $55.50 \pm 12.37$ \\
\hline RVD & $77.4 \pm 12.60$ & $71.5 \pm 8.90$ & $72.2 \pm 7.40$ & $70.50 \pm 7.93$ & $105.2 \pm 8.40$ & $106.00 \pm 11.20$ & $64.14 \pm 18.23$ & $70.4 \pm 31.38$ \\
\hline
\end{tabular}

BD: Bronchodilator; FEV1: Forced Expiratory Volume in the first second; FVC: Forced Vital Capacity; FEV1/FVC: Expiratory Volume Forced in the first second on Forced Vital Capacity; PFE: Peak Expiratory Flow; OVD: Obstructive Ventilatory Disorder; RVD: Restrictive Ventilatory Disorder. 
When we correlated the pairs of variables evaluated by spirometry with the anthropometric parameters of Weight and BMI, we observed an inverse relation between BMI and PEF, and between weight and spirometric parameters (FVC, FEV1 and PEF) and positive correlation between BMI and FEV1/FVC. In addition, PEF correlated with statistical significance with both BMI and Weight. The correlations and the values of $\mathrm{r}$ are described in Table 3.

\section{Discussion}

The present study aimed to describe the pulmonary function in obese adults and to correlate the evaluated parameters with Weight and BMI. In general, a higher prevalence of restrictive respiratory disorders was observed, although the obstructive ones were also present.

Bedell, et al., showed abnormalities of pulmonary function in obese people. However, they emphasized that the magnitude of these changes is variable in different individuals and is not necessarily associated with body weight and body mass index [20]. In contrast, it has been postulated that any mechanical interference in the diaphragmatic and/or thoracic cavity excursions is capable of causing a decrease in the capacity for lung expansion-reflected in FVC-as it may occur in pregnancy and obesity itself [20] [21]. Rasslan, et al., emphasize in their review that the most common alterations in respiratory function due to obesity are of two types: proportional changes to obesity (reduction of VRE [Expiratory Reserve Volume] and increase of diffusion capacity) and exclusive changes in grade III obesity (Reduction of Vital Capacity-VC and Total Pulmonary Capacity-TPC), resulting from the cycle involving distortions in the chest wall and respiratory mechanics, reduction of total compliance and reduction in pulmonary fluxes [21] [22] [23]. About this, Collins, et al., and Gontijo, et al., report that the predicted values of the spirometric parameters decrease according to the degree of obesity, especially FVC, FEV1 and Total Pulmonary Capacity (TPC) [7] [13] [24]. Our findings reinforce this assertion, with a decrease in FVC and FEV1 (83\% of predicted). Also, the FEV1/FVC ratio was unchanged and positively correlated with BMI which corroborates the Jones and Nzekwu (2006) study,

Table 3. Correlation of the variables Weight and BMI with the pulmonary function test.

\begin{tabular}{ccccc}
\hline \multirow{2}{*}{$\begin{array}{c}\text { Spirometric } \\
\text { parameters }\end{array}$} & Weight $(\mathbf{k g})$ & Value of $\boldsymbol{r}$ & BMI $\left(\mathbf{k g} / \mathbf{m}^{2}\right)$ & Value of $\boldsymbol{r}$ \\
\cline { 2 - 4 } FVC & Negative $^{*}$ & 0.42 & S/R & - \\
FEV1 & Negative & 0.43 & S/R & - \\
PEF & Negative & 0.11 & Negative & 0.49 \\
FEV1/FVC & S/R & - & Positive $^{*}$ & 0.23 \\
\hline
\end{tabular}

BMI: Body Mass Index; FEV1: Forced Expiratory Volume in the first second; FVC: Forced Vital Capacity; PEF: Expiratory Flow Peak; FEV1/FVC: Expiratory Volume Forced in the first second on Forced Vital Capacity. Value of $\mathrm{r}$-correlation coefficient. Negative correlation: inversely proportional variables. Positive correlation: directly proportional variables. S/R-without statistical correlation. ${ }^{*}$ Statistical significance with $\mathrm{p}$ value $<0.05$. 
who concluded that the higher the BMI, more direct the correlation [25]. However, we should observe these results with caution, since the correlation coefficient between the variables, in the present study, presented a reduced value (0.23). This result, although controversial because of the low $\mathrm{N}$, corroborates the study by Melo, et al., in which the pulmonary function of 140 individuals classified in six degrees of BMI was analyzed. The authors found an inverse relation between BMI and spirometry parameters, especially for obese individuals above $45 \mathrm{~kg} / \mathrm{m}^{2}$, suggesting a linear reduction in function due to the increase in BMI [26].

Domingos-Benício, et al., in their comparative study between obese and eutrophic individuals, did not found pulmonary function alterations that could be explained by obesity [27]. Interestingly, this finding can be explained by the anthropometric differences between the sample studied-mainly composed of women-since fat deposition is predominantly gynoid (hips and thighs), whereas in men it occurs predominantly in the abdomen (android phenotype) [22]. Hari-Klan, et al., described the relation between the distribution of body fat in both genders and lung function, in the study of individuals of both genders, and observed an inverse and significant association between WHR (Waist-Hip), FEV1 and CV only in men. As a conclusion, the authors suggested that the distribution of thoracoabdominal fat in man interferes in ventilatory mechanics more markedly than in women [28]. As a result, the male population would be more susceptible to the respiratory consequences of obesity. As we did not evaluate eutrophic control group, and our sample $\mathrm{N}$ was insufficient for staging by sex, we cannot corroborate with such facts.

In our evaluation of ventilatory disorders, we found a higher prevalence of restrictive disorders (23\%), which represents a certain unanimity among the studies, according to a large literature [7] [12] [13] [14] [15] [23] [24]. However, from a clinical point of view, obesity has also been correlated with obstructive ventilatory disorders, such as bronchial asthma and obstructive sleep apnea [29] [30], which supports our findings of obstructive ventilatory disorders in $18 \%$ of participants. It should be noted, however, that none of those evaluated had, according to anamnesis collected, a previous history of respiratory clinical disorders, which indicates the asymptomatic nature of these alterations.

Regarding the possible correlations between the variables and the parameters of spirometry, we found a negative association - that is, inversely proportional between body weight and FVC, FEV1 and PEF, whereas BMI correlated inversely with PEF alone. Ribeiro, et al., however, showed an inverse relation of BMI with FEV1, FEV1/FVC, FEF25-75 and VRE, although with little statistical significance, suggesting obstructive processes in small airways [11]. Similar results to those observed by Rasslan, et al., for the male population [22]. Ghobain, M.A. found only PEF reduction in its obese population evaluated with spirometry compared to the non-obese group. For the author, this is the result of the increase in total respiratory resistance and airways that occurs in obesity, added to different ethnicities and in some cases, methodologies, which may reflect hete- 
rogeneous results [31]. Finally, we emphasize the importance of extending these evaluations to the most numerically significant populations staged not only by sex, but also by different degrees of obesity, which reflects a limitation of the present study. We also corroborate the need for research on other independent variables, such as body weight, waist circumference and waist-hip ratio, because the measurement only of the body mass index has limitations and questionings.

\section{Conclusion}

The present study evidences the diversity of respiratory consequences due to obesity, with restrictive ventilatory disorders being more prevalent than obstructive, which was associated with the linear reduction of FVC, FEV1 and PEF values evaluated in spirometry and inversely correlated with body weight.

\section{Acknowledgements}

To the psychology team of the Bariatric Surgery Program of the Adriano Jorge Hospital Foundation (FHAJ) and to the Foundation for Research Support of the State of Amazonas (FAPEAM) (Manaus, AM-Brazil).

\section{References}

[1] World Health Organization (1998) Obesity: Preventing and Managing the Global Epidemic-Report of a WHO Consultation on Obesity. Report, World Health Organization, Geneva.

[2] Marcelino, L.F. and Patrício, Z.M. (2011) The Complexity of Obesity and the Process of Living after Bariatric Surgery: A Collective Health Issue. Science \& Collective Health, 16, 4767-4776.

[3] Fontaine, K.R. and Barofsky, I. (2001) Obesity and Health-Related Quality of Life. Obesity Research, 3, 173-182. https://doi.org/10.1046/j.1467-789x.2001.00032.x

[4] World Health Organization (2016) Obesity and Overweight. http://www.who.int/mediacentre/factsheets/fs311/en/

[5] INAN (1991) Nutritional Conditions of the Brazilian Population: Adults and the Elderly. National Research on Health and Nutrition. National Institute of Food and Nutrition, Ministry of Health, Brasília.

[6] Wanderley, E.M. and Ferreira, V.A. (2010) Obesity: A Plural Perspective. Ciência \& Saúde Coletiva, 15, 185-194. https://doi.org/10.1590/S1413-81232010000100024

[7] Gontijo, P.L., Lima, T.P., Costa, T.R., Reis, E.P., Cardoso, F.P.F. and Neto, F.F.C. (2011) Correlation of Spirometry with the Six-Minute Walk Test in Eutrophic and Obese Patients. Revista Da Associacao Medica Brasileira, 57, 387-393. https://doi.org/10.1590/S0104-42302011000400010

[8] Carvalho, E.A.A., Simão, M.T.J., Fonseca, M.C., et al. (2013) Obesity: Epidemiological Aspects and Prevention. Revista Da Associacao Medica Brasileira, , 23 , 74-82.

[9] Marques-Lopes, I., Marti, A., Moreno-Aliaga, M.J. and Martínez, A. (2004) Aspectos Gênicos da Obesidade. Nutrition Reviews, 17, 327-338. https://doi.org/10.1590/S1415-52732004000300006

[10] Pereira, L.O., Francischi, R.P. and Lancha, J.R. (2003) Obesity: Nutritional Habits, Sedentary Lifestyle and Insulin Resistance. Brazilian Archives of Metabolic Endocrinology, 47, 111-127. 
[11] Rey-Lopez, J.P., de Rezende, L.F., de Sá, T.H. and Stamatakis, E. (2015) Is the Metabolically Healthy Obesity Phenotype an Irrelevant Artifact for Public Health? American Journal of Epidemiology, 182, 737-741. https://doi.org/10.1093/aje/kwv177

[12] Ribeiro, G.F., Araújo, L.M.B., Souza-Machado, A. and Ribeiro, P.A. (2007) Evaluation of Pulmonary Function in Obese Asymptomatic Respiratory Subjects: Correlation between Anthropometric and Spirometric Data. Revista Brasileira de Alergia e Imunopatologia, 30, 227-231.

[13] Wang, S., Sun, X., Hsia, T-C., Lin, X. and Li, M. (2017) The Effects of Body Mass Index on Spirometry Tests among Adults in Xi'an, China. Medicine, 96, e6596. https://doi.org/10.1097/MD.0000000000006596.

[14] Melo, L.C., da Silva, M.A.M. and do Nascimento Calles, A.C. (2014) Obesity and Pulmonary Function: A Systematic Review. Einstein, 12, 120-125.

[15] Rasslan, Z., Stirbulov, R., Lima, C.A.C. and Junior, R.S. (2009) Pulmonary Function and Obesity. Revista Brasileira de Clínica Médica, 7, 36-39.

[16] Stirbulov, R. (2007) Respiratory Repercussions of Obesity. Brasileiro de Pneumologia, 33, 7-8.

[17] American Thoracic Society/European Respiratory Society (2002) ATS/ERS Statement on Respiratory Muscle Testing. American Journal of Respiratory and Critical Care Medicine, 166, 518-624. https://doi.org/10.1164/rccm.166.4.518

[18] Brazilian Society of Pulmonology and Tisiology (2002) Guidelines for Lung Function Tests. Jornal Brasileiro de Pneumologia, 28, S1-S238.

[19] Global Initiative for Chronic Obstructive Lung Disease (2015) Global Strategy for the Diagnosis, Management, and Prevention of Chronic Obstructive Pulmonary Disease. http://www.goldcopd.org

[20] Bedell, G.N., Wilson, W.R. and Seebohm, P.M. (1958) Pulmonary Function in Obese Person. Journal of Clinical Investigation, 37, 1049-1060. https://doi.org/10.1172/JCI103686

[21] Lean, M.E., Han, T.S. and Morrison, C.E. (1995) Waist Circumference as a Measure for Indicating Need for Weight Management. British Medical Journal, 311,158-161. https://doi.org/10.1136/bmj.311.6998.158

[22] Sahebjami, H. (1998) Dyspnea in Obese Healthy Men. Chest, 114, 1373-1377. https://doi.org/10.1378/chest.114.5.1373

[23] Rasslan, Z., Saad Junior, R., Stirbulov, R., Fabbri, R.M.A. and Lima, C.A.C. (2004) Evaluation of Lung Function in Obesity Grades I and II. Brazilian Journal of Pulmonology, 30, 508-514.

[24] Collins, C.L., Hoberty, P.D., Walker, J.F., Fletcher, E.C. and Peiris, A.N. (1995) The Effects of Body Fat Distribution on Pulmonary Function Tests. Chest, 107, 1298-1302. https://doi.org/10.1378/chest.107.5.1298

[25] Jones, R.L. and Nzekwu, M.U. (2006) The effects of Body Mass Index on Lung Volumes. Chest, 130, 827-833. https://doi.org/10.1378/chest.130.3.827

[26] Melo, S.A.D., de Melo, V.A., Menezes Filho, R.S. and Santos, F.A. (2011) Efeitos do aumento progressivo do peso corporal na função pulmonar em seis grupos de índice de massa corpórea. Revista da Associação Médica Brasileira, 57, 509-515. https://doi.org/10.1590/S0104-42302011000500007

[27] Domingos-Benicio, N.C., Gastaldi, A.C., Perecin, J.C, Avena, K.M., Guimaraes, R.C., Sologuren, M.J.J., et al. (2004) Spirometric Measurements in Obese People in Orthostatic, Sitting and Lying Positions. Revista da Associação Médica Brasileira, 50, 142-147. 
[28] Hari-Klan, R.I., Fleg, J.L. and Wise, R.A. (2001) The Effect of Gender of the Relationship between Body Fat Distribution and Lung Function. Journal of Clinical Epidemiology, 54, 339-406.

[29] Hintze, L.J., Bevilaqua, C.A., Pimentel, E.B. and Nardo-Junior, N. (2011) Bariatric Surgery in Brazil. Revista Ciências Médicas, 20, 87-98.

[30] De Oliveira, P.D., Wehrmeister, F.C., Pérez-Padilla, R., Gonçalves, H., Assunção, M.C.F., Horta, B.L., et al. (2016) Relationship between Body Composition and Pulmonary Function in Early Adult Life: A Cross-Sectional Analysis Nested in Two Birth Cohort Studies. Public Library of Science, 11.

[31] Al Ghobain, M. (2012) The Effect of Obesity on Spirometry Tests among Healthy Non-Smoking Adults. BMC Pulmonary Medicine, 12, 10.

https://doi.org/10.1186/1471-2466-12-10

Submit or recommend next manuscript to SCIRP and we will provide best service for you:

Accepting pre-submission inquiries through Email, Facebook, LinkedIn, Twitter, etc. A wide selection of journals (inclusive of 9 subjects, more than 200 journals) Providing 24-hour high-quality service User-friendly online submission system Fair and swift peer-review system Efficient typesetting and proofreading procedure Display of the result of downloads and visits, as well as the number of cited articles Maximum dissemination of your research work

Submit your manuscript at: http://papersubmission.scirp.org/

Or contact health@scirp.org 